\title{
Effects of yak-activated protein on hematopoiesis and related cytokines in radiation-induced injury in mice
}

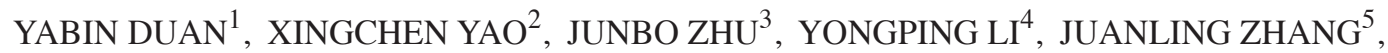 \\ XUEJIAO ZHOU ${ }^{5}$, YIJIE QIAO ${ }^{3}$, MENG YANG $^{5}$ and XIANGYANG LI $^{6,7}$ \\ ${ }^{1}$ Department of Clinical Pharmacy, Qinghai University Affiliated Hospital, Xining, Qinghai 810001; \\ ${ }^{2}$ Department of Radiotherapy Oncology, Qinghai People's Hospital, Xining, Qinghai 810007; \\ Departments of ${ }^{3}$ Pharmacy and ${ }^{4}$ Traditional Chinese Medicine, Medical College, Qinghai University, \\ Xining, Qinghai 810001; ${ }^{5}$ Department of Biology Resources, College of Eco-Environmental Engineering, \\ Qinghai University, Xining, Qinghai 810016; ${ }^{6}$ Medical College and ${ }^{7}$ State Key Laboratory of Plateau \\ Ecology and Agriculture, Qinghai University, Xining, Qinghai 810016, P.R. China
}

Received April 20, 2016; Accepted March 24, 2017

DOI: $10.3892 / \mathrm{etm} .2017 .5256$

\begin{abstract}
The aim of the present study was to investigate the protective effects of yak-activated protein on hematopoiesis and cytokine function in radiation-induced injury in mice. A total of 180 Kunming mice were randomly divided into three groups (A, B and C). Of these, 60 were randomly divided into a normal control group, a radiation model group, a positive control group and 3 yak-activated protein groups (high, medium and low dose groups; 10,5 and $2.5 \mathrm{mg} / \mathrm{kg}$, respectively). The other 120 mice were used for the subsequent experiments on days 7 and 14 following radiation. Yak-activated protein was administered orally to mice in the treatment groups and an equal volume of saline was administered orally to mice in the normal control and radiation model groups for 14 days. The positive control group received amifostine $(150 \mathrm{mg} / \mathrm{kg})$ via intraperitoneal injection. With the exception of the control group, the groups of mice received a 5 Gy quantity of X-radiation evenly over their whole body once. Changes in the peripheral hemogram, thymus and spleen indices, DNA content in the bone marrow, interleukin (IL)-2 and IL-6 levels, and the expression levels of B cell lymphoma $2(\mathrm{Bcl}-2)$ and $\mathrm{Bcl}-2$-associated $\mathrm{X}$ protein (Bax) following irradiation were assessed. The low dose of yak-activated protein significantly increased Spleen indices in mice 14 days after irradiation and the high and middle dose of yak-activated protein significantly increased Thymus indices in mice 14 days after irradiation $(\mathrm{P}<0.05)$ compared with the control group. In addition, hemogram results increased gradually in the low-yak-activated protein dose group and were
\end{abstract}

Correspondence to: Dr Xiangyang Li, Medical College, Qinghai University, 251 Ningda Road, Xining, Qinghai 810016, P.R. China E-mail: qhmclxy@163.com

Key words: yak-activated protein, radiation injury, hematopoiesis, cytokines significantly higher 7 days after irradiation compared with the radiation model group $(\mathrm{P}<0.05)$. The DNA content in the bone marrow was markedly increased in the yak-activated protein groups, and increased significantly in the low dose group at 7 days post-irradiation compared with the radiation model group $(\mathrm{P}<0.05)$. The IL-2 content was significantly increased in the yak-activated protein groups $(\mathrm{P}<0.05)$. Furthermore, Bcl-2 expression was increased and Bax expression was decreased $(\mathrm{P}<0.05)$. These results suggest that yak-activated protein exerts protective effects against radiation-induced injury in mice. The optimal effects of yak-activated protein were observed in the medium dose group 14 days after irradiation.

\section{Introduction}

Ionizing radiation has positive applications in agricultural production, medicine and health, scientific research and national defense (1). However, it also damages many aspects of human physiology, including the peripheral blood cells, bone marrow DNA (2), immune-related organs (3) and antioxidant enzymes $(4,5)$. The United States Army Research Institute developed the first anti-radiation drug, amifostine, which was approved by the United States Food and Drug Administration (6). Amifostine is able to significantly reduce the death of normal cells following radiotherapy; however, side effects including hypotension, nausea, vomiting and other adverse reactions have restricted its use (7). Therefore, studies are warranted to identify an effective, natural non-toxic medicine that protects against radiation and reduces radiation damage. Previous studies have documented that plant proteins $(8,9)$ and non-heme iron-binding proteins (10-12) exert protective effects against radiation. In addition, arginine, glutamine, glycine, mycosporine-like amino acids and essential amino acids may promote weight recovery, improve protein nutritional conditions and exert anti-oxidant effects in rats exposed to X-ray irradiation (13-15).

A previous study from the authors revealed that Yak-activated proteins are extracted from the healthy tissue 
of yaks from the Qinghai-Tibetan Plateau, and have been found to contain a large number of small peptides (not published). Yak-activated protein was initially identified following treatment of isolated yak tissues with a combination of radiotherapy and chemotherapy, whereby the mature white blood cell count was found to be normal, while the activity of $\mathrm{T}$ cells, natural killer cells, monocytes and neutrophils was unusually high. Isolated yak tissue is typically prepared using extraction, separation and purification methods with applied modern biotechnology and biological engineering technologies, allowing it to be absorbed directly without digestion in the intestinal tract. There are many sources of yak-activated protein in the Qinghai-Tibetan Plateau. Yak-activated protein provides rich nutrition without toxicity, does not accumulate in the body and acts as a multifunctional factor (16). Furthermore, it is able to inhibit tumor growth, increase the number of white blood cells and regulate the immune system (17).

The aim of the present study was to evaluate the effect of yak-activated protein on peripheral blood cells, immune function, bone marrow DNA content, antioxidant enzyme activity and the expression of apoptosis-related proteins in radiation-induced injury in mice. The underlying mechanisms regarding the potential protective effects of yak-activated protein were also investigated. Results of the current study may indicate novel methods of studying radiation-protective agents and the clinical applications of yak-activated protein.

\section{Materials and methods}

Materials and reagents. Yak-activated protein was purchased from Tibet Buzhengtang Bio-tech Engineering Co. Ltd., (Lhasa, China). High performance liquid chromatography (HPLC)-grade acetonitrile was obtained from Shandong Yuwang Industrial Co., Ltd. (Yucheng, China). Amifostine (cat. no. 130306) was purchased from Tianjin Zhongrui Pharmaceutical Co., Ltd. (Tianjin, China). ELISA kits for measurements of mouse B cell lymphoma 2 (Bcl-2; cat. no. 20141227.60284M), mouse Bcl-2-associated X protein (Bax; cat. no. 20141227.60283M), mouse interleukin 2 (IL-2; cat. no. 20141227.60019M), and mouse IL-6 (cat. no. 20141227.60023M) were purchased from Beijing RigorBio Science Development Co., Ltd. (Beijing, China). Blood cell hemolysis reagent (cat. no. 2013111101), class III probe cleaning fluid (cat. no. 2013112101) and dilution buffer for blood cell analysis (M-23D; cat. no. 2013110701) were purchased from Shenzhen Mindray Bio-Medical Electronics Co., Ltd. (Shenzhen, China). All other standard laboratory reagents were chemically pure and the water used was purified. HPLC was performed using a Waters 515 High Performance Liquid Chromatograph (Waters Corporation, Milford, MA, USA), a medical electronic linear accelerator (23EX; Varian Medical Systems, Inc., Palo Alto, CA, USA) and a UV-2550 ultraviolet spectrophotometer (Labtech International, Ltd., Uckfield, UK). A TGL-16 B high speed-freezing centrifuge was obtained from the Shanghai Anting Scientific Instrument Factory (Shanghai, China). An RT-2100C enzyme-labeled meter was sourced from Rayto Life and Analytical Sciences Co., Ltd. (Shenzhen, China) and an XW-80A Vortex mixer was purchased from Shanghai Medical Instruments Ltd., Corp.
(Shanghai, China). A BC-2300quasi automatic three-classification blood cell analyzer was purchased from Shenzhen Mindray Bio-Medical Electronics C. Ltd.

Sample hydrolysis. Yak-activated protein $(33.5 \mathrm{mg})$ was placed in a $10-\mathrm{ml}$ ampere bottle and $6 \mathrm{ml} \mathrm{HCl}(6 \mathrm{~mol} / \mathrm{l})$ was added. The vial was sealed and incubated for $24 \mathrm{~h}$ at $110^{\circ} \mathrm{C}$ for sample hydrolysis. The sample was then cooled at room temperature for $40 \mathrm{~min}$, filtered (pore size, $0.5 \mu \mathrm{m}$ ) and the filter liquor was added to a $15-\mathrm{ml}$ tube. The tube was vacuum dried at $90^{\circ} \mathrm{C}$ in a Multivapor evaporator. Following drying, the residue was dissolved in water and the aforementioned step was repeated. Finally, the evaporated residue was dissolved in $5 \mathrm{ml} \mathrm{HCl}$ (20 mmol). The sample had undegone hydrolysis when the vial was sealed and incubated for $24 \mathrm{~h}$ at $110^{\circ} \mathrm{C}$. Following filtration to remove impurities, the sample was contained in the filter liquor, and then $\mathrm{HCl}(20 \mathrm{mmol})$ was added to dissolve the sample.

Sample derivatization. Samples $(0.4 \mathrm{ml})$ were added to $1 \mathrm{ml}$ sodium bicarbonate $(0.5 \mathrm{~mol} / \mathrm{l})$ and $0.4 \mathrm{ml}$ fluorobenzene acetonitrile solution $(1 \%)$ in a volumetric flask $(10 \mathrm{ml})$. The flask was incubated at $60^{\circ} \mathrm{C}$ for $1 \mathrm{~h}$ and a potassium dihydrogen phosphate buffer solution $(0.1 \mathrm{~mol} / \mathrm{l}, \mathrm{pH} 7)$ was added. The mixture was filtered through a microporous membrane (pores $0.22 \mu \mathrm{m}$ ), then immediately subjected to high-performance liquid chromatography, as follows.

Chromatographic detection conditions. The following chromatographic conditions were used: Column, Phenomenex Gemini $5 \mu$ C18 (250x4.6 mm; Phenomenex, Inc., Torrance, CA, USA); detection wavelength, $360 \mathrm{~nm}$; column temperature, $37^{\circ} \mathrm{C}$; flow rate, $1 \mathrm{ml} / \mathrm{min}$, sample load, $8 \mu \mathrm{l}$; and a gradient elution of mobile phase A $(0.05 \mathrm{~mol} / 1$ sodium acetate; $\mathrm{pH}$ 6.4) and mobile phase B (acetonitrile: water=1:1; Table I).

Animals groups and dose regimens. A total of 180 male Kunming mice (6-8 weeks old, 22-25 g) were purchased from the Experimental Animal Center of Gansu University of Traditional Chinese Medicine (Lanzhou, China). The animals were adapted for a week at $23 \pm 2^{\circ} \mathrm{C}$ with a constant humidity of $55 \pm 5 \%$ under a 12-h light-dark cycle and with ad libitum access to water and food pellets. There were 10 animals housed per cage. A total of 60 mice were randomly divided into normal control, irradiated control, positive control (amifostine, $150 \mathrm{mg} / \mathrm{kg}$ ) and high, medium and low dose yak-activated protein groups $(10,5$ and $2.5 \mathrm{mg} / \mathrm{kg}$, respectively; $\mathrm{n}=10$ ). The other 120 mice were used for subsequent experiments on days 7 and 14 after radiation, respectively, in order to assess the changes in various indicators at different time points. The normal control and irradiated control groups received normal saline orally, and all other treatment groups were administered yak-activated protein $(10,5$ or $2.5 \mathrm{mg} / \mathrm{kg})$ orally for 14 days. The mice in the positive control group were treated with an intraperitoneal injection of amifostine $(150 \mathrm{mg} / \mathrm{kg}) 30 \mathrm{~min}$ prior to irradiation. Mice were anesthetized with $50 \mathrm{mg} / \mathrm{kg}$ enterocoelia injection of $1 \%$ sodium pentobarbital (Propbs Bio-tech Co. Ltd, Beijing, China) prior to experiments. 
Radiation damage model. The QingHai University Affiliated Hospital was used for the irradiation experiment. All mice, with the exception of the control group, were restrained in special boxes and exposed to 5.0 Gy total-body X-radiation at a does rate of $300 \mathrm{cGy} / \mathrm{min}$ once. The source-to-animal distance was $100 \mathrm{~cm}$. Radiation time: $100 \mathrm{sec}(18,19)$. Following exposure to radiation, 180 mice were used on days 3,7 and 14 .

Sample collection. Mice were anesthetized with enterocoelia injection of $50 \mathrm{mg} / \mathrm{kg} 1 \%$ sodium pentobarbital prior to experiments. Ocular blood was harvested from the mice in all treatment groups 7 days after irradiation. Each sample was mixed with EDTA-2Na (Mingyuan Industry Co., Ltd, Zhengzhou, China) to prevent coagulation, and the remainder was coagulated to separate the serum by centrifugation at $1,000 \times \mathrm{g}$ for $10 \mathrm{~min}$ at $4^{\circ} \mathrm{C}$. All mice were sacrificed with enterocoelia injection of $50 \mathrm{mg} / \mathrm{kg} 5 \%$ sodium pentobarbital at 3, 7 and 14 days following irradiation ( $n=60$ for all groups). After sacrifice, the thymus and spleen (without fat) were harvested, rinsed with saline to remove blood, dried using filter paper and weighed.

Cell counts and organ indices. Blood cell diluents (catalogue no. M-23D, lot 2013110701; Mindray Bio-Medical Electronics Co., Ltd, Shenzhen, China) were added in to $20 \mu \mathrm{l}$ ocular blood following the manufacturers protocol. Blood cell count (leucocytes-WBC, erythrocytes-RBC, hemoglobin-HGB and thrombocytes-PLT) was determined using BC-2300 blood cell analyzer (Mindray Bio-Medical Electronics Co., Ltd.). The organ indices were calculated using the following formula: Organ index $(\%)=$ Organ weight $(\mathrm{g}) /$ animal weight (g) x 100 (20).

DNA content of bone marrow. Mice were sacrificed following the harvest of ocular blood. The right femur was isolated and muscle tissue and blood were removed. One side of the femoral head was cut and $10 \mathrm{ml} \mathrm{CaCl}{ }_{2}(0.005 \mathrm{~mol} / \mathrm{l})$ was used to flush the bone marrow into a centrifuge tube. The bone marrow was placed in a refrigerator at $4^{\circ} \mathrm{C}$ for $30 \mathrm{~min}$, then centrifuged at $693 \mathrm{x} \mathrm{g}$ for $15 \mathrm{~min}$ at $4^{\circ} \mathrm{C}$. The supernatant was discarded and $5 \mathrm{ml} 0.2 \mathrm{~mol} / 1 \mathrm{HClO}_{4}$ was used to acidify the precipitate. The precipitate was then agitated, heated to $90^{\circ} \mathrm{C}$ for $15 \mathrm{~min}$, cooled, centrifuged at $1,350 \mathrm{x}$ g for $10 \mathrm{~min}$ at $4^{\circ} \mathrm{C}$ and filtered (pores $50 \mu \mathrm{m}$ ). The absorbance (A) of the supernatant was determined using a UV spectrophotometer at $268 \mathrm{~nm}$. DNA content was calculated according to the following formula: DNA $(\mu \mathrm{g})=40 \times 50 \times A(21)$.

IL-2 and IL-6 content and Bcl-2 and Bax expression. ELISA kits (Bcl-2; cat. no. 20141227.60284M; Bax; cat. no. 20141227.60283M; IL-2; cat. no. 20141227.60019M; IL-6; cat. no. 20141227.60023M; Beijing RigorBio Science Development Co., Ltd.) were used to measure the levels of IL-2, IL-6, Bcl-2 and Bax in the serum, according to the manufacturer's protocol.

Statistical analysis. All quantitative data are expressed as the mean \pm standard deviation. The data were analyzed using one-way analysis of variance with SPSS 17.0 software (SPSS, Inc., Chicago, IL, USA), and the differences between the
Table I. Amino acid samples separated by gradient elution chromatography.

\begin{tabular}{lc}
\hline Time, min & $\begin{array}{c}\text { Solvent A }(0.05 \mathrm{~mol} / \mathrm{l} \\
\text { sodium acetate; } \mathrm{pH} 6.4), \%\end{array}$ \\
\hline $0-5$ & $74-65$ \\
$5-15$ & $65-60$ \\
$15-20$ & $60-45$ \\
$20-25$ & $45-30$ \\
$25-30$ & $30-20$ \\
$30-35$ & $20-2$ \\
$35-40$ & $2-2$ \\
$40-42$ & $2-74$ \\
\hline
\end{tabular}

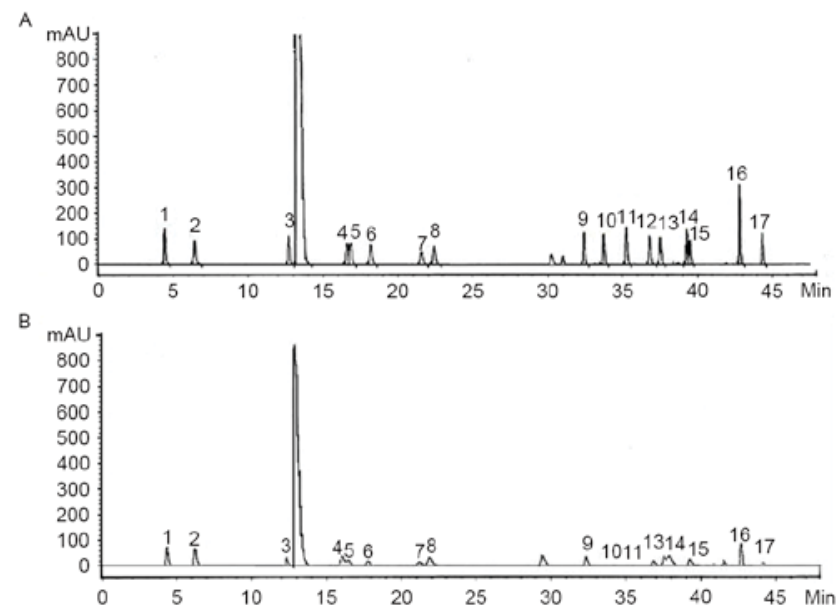

Figure 1. High performance liquid chromatogram of the (A) standards and (B) samples. 1, Asp; 2, Ser; 3, Glu; 4, Gly; 5, His; 6, Arg; 7, Thr; 8, Ala; 9, Pro; 10, Cys; 11, Tyr; 12, Val; 13, Met; 14, Lys; 15, Ile; 16, Leu; 17, Phe.

means of two groups were compared using a least significant difference test. $\mathrm{P}<0.05$ was considered to indicate a statistically significant difference.

\section{Results}

Amino acid content of yak-activated protein. Amino acid content of yak-activated protein: ASP (1.5\%), Glu (2.04\%), Ser $(0.73 \%)$, Arg (1.30\%), Thr (1.03\%), Pro (1.06\%), Ala (0.98\%), Val $(0.52 \%)$, Met $(0.06 \%)$, Cys $(0.09 \%)$, Ile $(0.36 \%)$, Leu $(0.57 \%)$, Phe $(0.72 \%)$, His $(0.34 \%)$, Lys $(1.61 \%)$ and Tyr $(0.15 \%)$ as presented in Fig. 1. The methods are accurate, convenient, reliable and may be replicated, for the determination of amino acid content of yak-activated protein. The amino acid content of yak-activated protein is presented in Table II, and the chromatogram is displayed in Fig. 1.

Effect of yak-activated protein on the peripheral hemograms of mice following irradiation. The peripheral hemograms of irradiated mice are presented in Fig. 2. In the radiation model group, it was observed that WBC and PLT declined significantly on days 3 and 7, respectively, compared with the normal control group ( $\mathrm{P}<0.05$; Fig. 2). Furthermore, RBC 

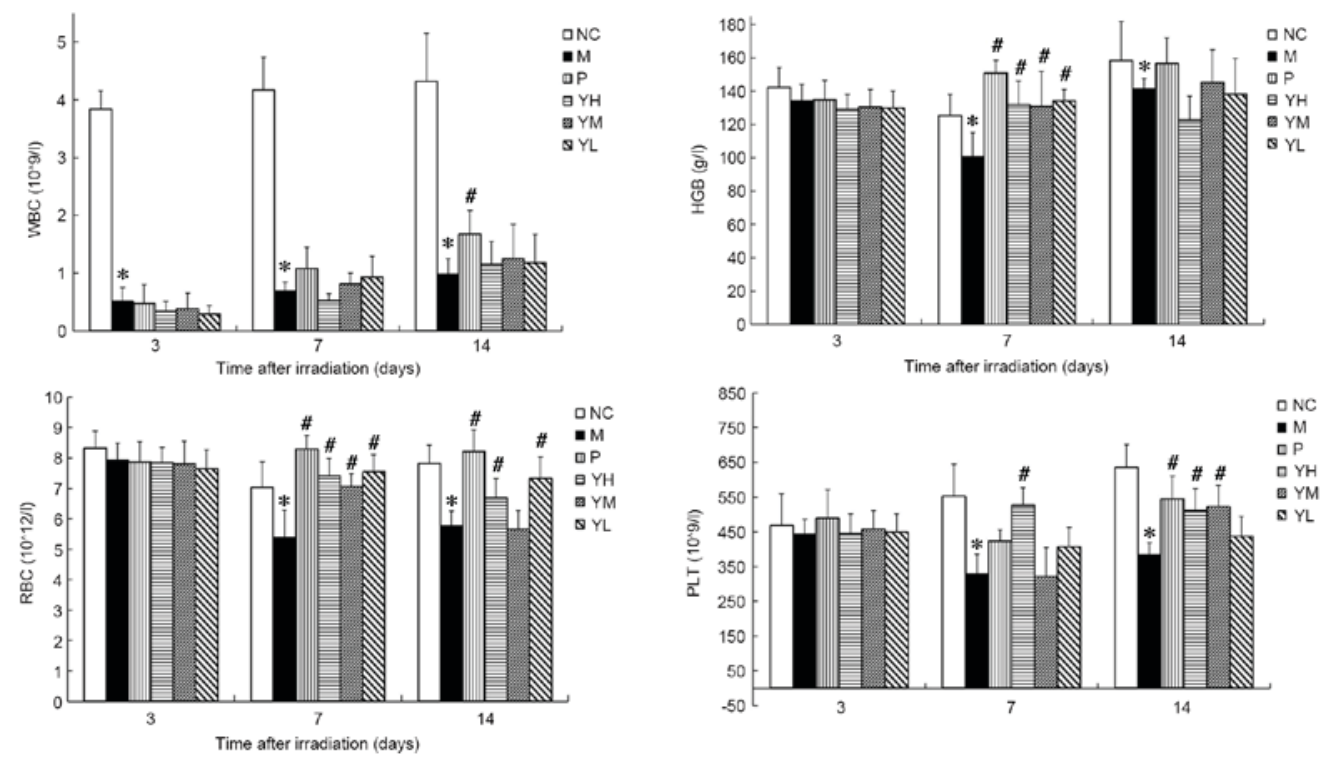

Figure 2. Effect of yak-activated protein on the peripheral hemograms of irradiated mice. Data are expressed as the mean + standard error of the mean. $\mathrm{n}=10$ per group. ${ }^{\text { }} \mathrm{P}<0.05$ vs. normal control group, ${ }^{~} \mathrm{P}<0.05$ vs. model group. $\mathrm{NC}$, normal control; $\mathrm{M}$, radiation model; $\mathrm{P}$, positive control; $\mathrm{YH}, \mathrm{high}$ dose $(10 \mathrm{mg} / \mathrm{kg})$ yak-activated protein; YM, medium-dose (5 mg/kg) yak-activated protein; YL, low-dose $(2.5 \mathrm{mg} / \mathrm{kg}$ ) yak-activated protein; WBC, white blood cell; HGB, hemoglobin; RBC, red blood cell; PLT, platelet.

Table II. Amino acid content of yak-activated protein.

\begin{tabular}{lc}
\hline Amino acid & Content $(\%)$ \\
\hline Asp & 1.50 \\
Glu & 2.04 \\
Ser & 0.73 \\
Gly & 0.73 \\
Arg & 1.30 \\
Thr & 1.03 \\
Pro & 1.06 \\
Ala & 0.98 \\
Val & 0.52 \\
Met & 0.06 \\
Cys & 0.09 \\
Ile & 0.36 \\
Leu & 0.57 \\
Phe & 0.72 \\
His & 0.34 \\
Lys & 1.61 \\
Tyr & 0.15 \\
\hline
\end{tabular}

count and HGB levels declined significantly and reached a minimum 7 days after irradiation $(\mathrm{P}<0.05$ vs. normal control group). These results suggest that the radiation damage model was successfully established. The WBC, RBC, HGB and PLT count no significant different was observed between the positive control group and yak-activated protein groups (low, medium and high dose) 3 or 7 days after irradiation (P>0.05; Fig. 2). On day 14 after irradiation, the WBC of the positive group was significantly higher than yak-activated protein groups (low, medium and high dose groups; $\mathrm{P}<0.05$; Fig. 2); The RBC of the positive group was significantly higher than the medium dose of yak-activated protein $(\mathrm{P}<0.05$; Fig. 2). No significant difference was observed between the positive group and yak-activated protein groups (low, medium and high dose groups) in HBG (P>0.05; Fig. 2); The PLT of the positive group was significantly higher than yak-activated protein low dose group $(\mathrm{P}<0.05$; Fig. 2). Fig. 2 indicates that, compared with the WBC count of the control group the WBC counts of mice in the model group on days 3, 7 and 14 after irradiation were significantly reduced $(\mathrm{P}<0.05$; Fig. 2$)$. The WBC count of yak-activated protein groups were higher than model group on day 14 after irradiation, but no significant difference was observed ( $\mathrm{P}>0.05$; Fig. 2 ). The HGB of the positive and yak-activated protein groups was significantly higher than the model group on day 7 after irradiation $(\mathrm{P}<0.05$; Fig. 2$)$. On the 7th day after irradiation, the RBC count of mice in positive group and yak-activated protein groups (low, medium and high) compared with model was significantly increased $(\mathrm{P}<0.05$; Fig. 2). The RBC count of mice in positive, high and low dose yak-activated protein groups compared with model was significantly increased on day 14 ( $\mathrm{P}<0.05$; Fig. 2). On day 7 after irradiation, the PLT count of mice in high dose yak-activated protein groups compared with model was significantly increased $(\mathrm{P}<0.05$; Fig. 2). The PLT count of mice in positive, high and medium dose yak-activated protein groups compared with model was significantly increased $(\mathrm{P}<0.05$; Fig. 2) on day 14. These results suggest that Yak-activated protein significantly improved the hematopoietic system in radiation-injured mice.

Effect of yak-activated protein on the thymus and spleen indices of irradiated mice. The thymus and spleen indices of irradiated mice are presented in Fig. 3. Significant immune organ atrophy was observed in irradiated model mice compared with normal control mice at all time points (all $\mathrm{P}<0.05$; Fig. 3), thus indicating that the radiation damage model 

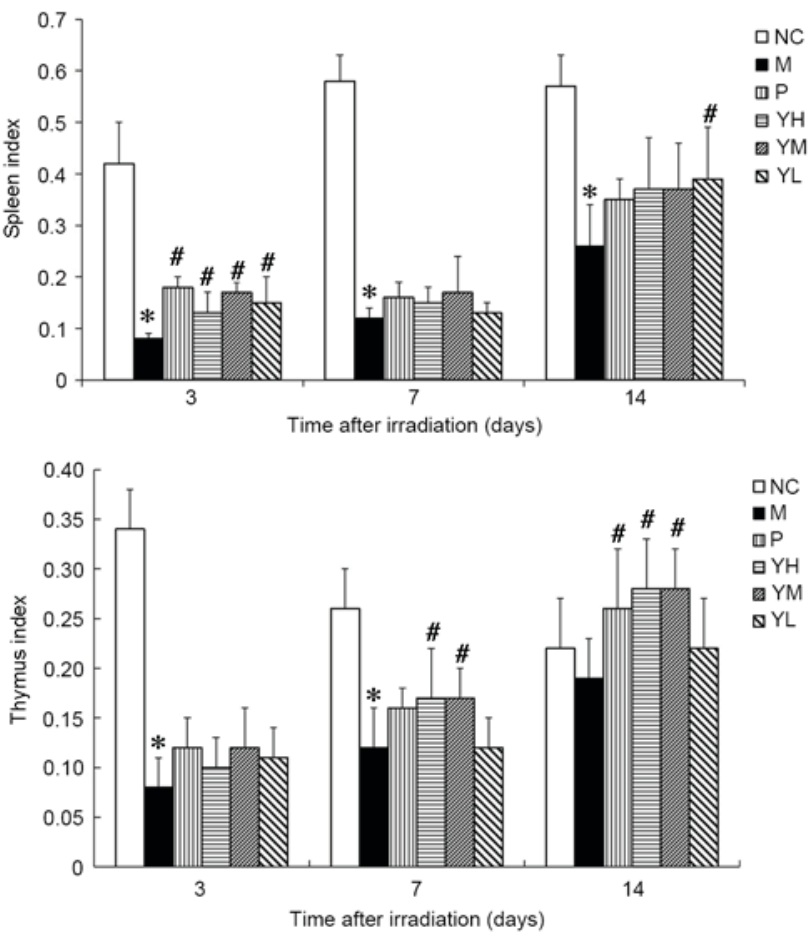

Figure 3. Effect of yak-activated protein on the thymus and spleen indices of irradiated mice. Data are expressed as the mean + standard error of the mean. $\mathrm{n}=10$ per group. ${ }^{*} \mathrm{P}<0.05$ vs. normal control group, ${ }^{\#} \mathrm{P}<0.05$ vs. model group. $\mathrm{NC}$, normal control; $\mathrm{M}$, radiation model; $\mathrm{P}$, positive control; $\mathrm{YH}$, high dose $(10 \mathrm{mg} / \mathrm{kg})$ yak-activated protein; YM, middle-dose $(5 \mathrm{mg} / \mathrm{kg})$ yak-activated protein; YL, low-dose $(2.5 \mathrm{mg} / \mathrm{kg})$ yak-activated protein.

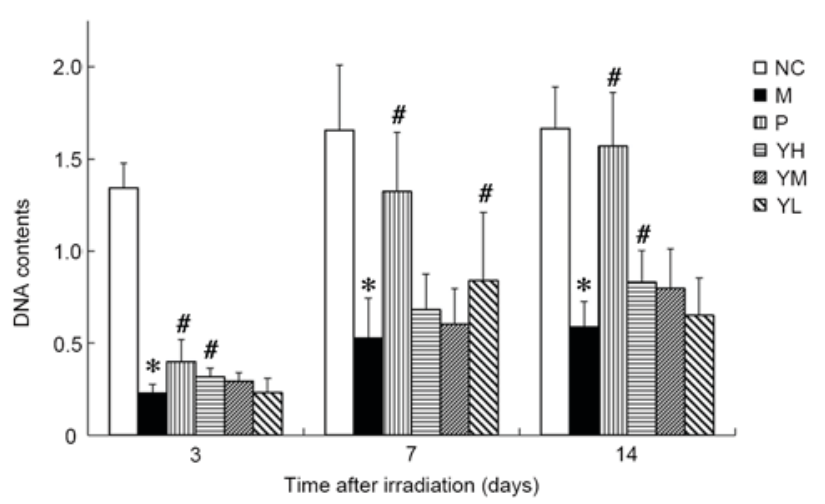

Figure 4. Effect of yak-activated protein on the bone marrow DNA content of irradiated mice. Data are expressed as the mean + standard error of the mean. $\mathrm{n}=10$ per group. ${ }^{*} \mathrm{P}<0.05$ vs. normal control group, ${ }^{*} \mathrm{P}<0.05$ vs. model group. $\mathrm{NC}$, normal control; $\mathrm{M}$, radiation model; $\mathrm{P}$, positive control; $\mathrm{YH}$, high dose $(10 \mathrm{mg} / \mathrm{kg})$ yak-activated protein; YM, middle-dose $(5 \mathrm{mg} / \mathrm{kg})$ yak-activated protein; YL, low-dose $(2.5 \mathrm{mg} / \mathrm{kg})$ yak-activated protein.

was successfully established. The spleen indices of the positive group and yak-activated protein groups were significantly higher than model group on day 3 after irradiation $(\mathrm{P}<0.05$; Fig. 3). On day 7 after irradiation, no significant difference was observed between the spleen indices in the positive or yak-activated protein with the model groups ( $\mathrm{P}>0.05$; Fig. 3 ). On day 14 after irradiation, the spleen indices of mice in the low dose yak-activated protein groups compared with model were significantly increased $(\mathrm{P}<0.05$; Fig. 3). On day 7 after irradiation, the thymus indices of mice in high and medium dose yak-activated protein groups compared with model was significantly increased $(\mathrm{P}<0.05$; Fig. 3$)$. On day 14 after irradiation, the thymus indices of mice in the positive, high and medium dose yak-activated protein groups compared with model was significantly increased $(\mathrm{P}<0.05$; Fig. 3$)$. These data indicate that yak-activated protein may promote immune organ recovery.

Effect of yak-activated protein on the bone marrow DNA content of irradiated mice. The DNA content in the bone marrow of irradiated mice is presented in Fig. 4. It was observed that the DNA content in the drug and radiation model groups was significantly decreased compared to that in the normal control group $(\mathrm{P}<0.05$; Fig. 4). The DNA content of all groups reached a minimum on day 3 post-irradiation. On day 3 after irradiation, the DNA content of mice in the positive and high dose yak-activated protein groups compared with model was significantly increased ( $\mathrm{P}<0.05$; Fig. 4). The DNA content in the bone marrow of mice in the low yak-activated protein and positive control groups was increased significantly compared with the irradiation control group on day 7 after irradiation $(\mathrm{P}<0.05$; Fig. 4). On day 14 after irradiation, the DNA content of mice in positive control and high dose yak-activated protein groups compared with model was significantly increased $(\mathrm{P}<0.05$; Fig. 4). This suggests that yak-activated protein and the positive control agent (amifostine) increased the bone marrow DNA content and improved the hematopoietic system following radiation.

IL-2 and IL-6 content. The IL-2 content was significantly higher in the radiation model group compared with the normal control group at all time points following irradiation $(\mathrm{P}<0.05$; Fig. 5). On day 3, the IL-2 content was significantly increased in the low and medium dose yak-activated protein groups (both $\mathrm{P}<0.05$; Fig. 5). By contrast, IL-2 content was significantly increased in only the high-dose yak-activated protein group on day 7 ( $\mathrm{P}<0.05$; Fig. 5). These data suggest that yak-activated protein may promote the expression and secretion of IL-2 in $\mathrm{X}$-ray irradiated mice. IL-2 content in the medium and low dose groups trended toward recovery on day 7, and a similar trend was observed in all yak-activated protein groups by day 14. These data suggest that yak-activated protein may regulate IL-2 in radiation injury.

On day 3 post-irradiation, IL- 6 content was significantly lower in the radiation model group compared with the normal control group $(\mathrm{P}<0.05$; Fig. 6$)$, while on day 7 , it was significantly higher compared with the normal control group $(\mathrm{P}<0.05$; Fig. 6). Levels of IL-6 did not differ significantly between the normal control and radiation model groups on day 14 . On day 3 , the IL-6 content was significantly increased in the medium dose yak-activated protein group compared with the radiation model group $(\mathrm{P}<0.05$; Fig. 6), suggesting that yak-activated protein promoted the expression and secretion of IL-6 in irradiated mice. On day 7, IL-6 levels were decreased significantly in all yak-activated protein-treated groups and in the positive control group (all $\mathrm{P}<0.05$ vs. model group; Fig. 6). On day 14, IL-6 content was significantly increased in the low dose yak-activated protein and positive control groups compared with the model group (both $\mathrm{P}<0.05$; Fig. 6). 


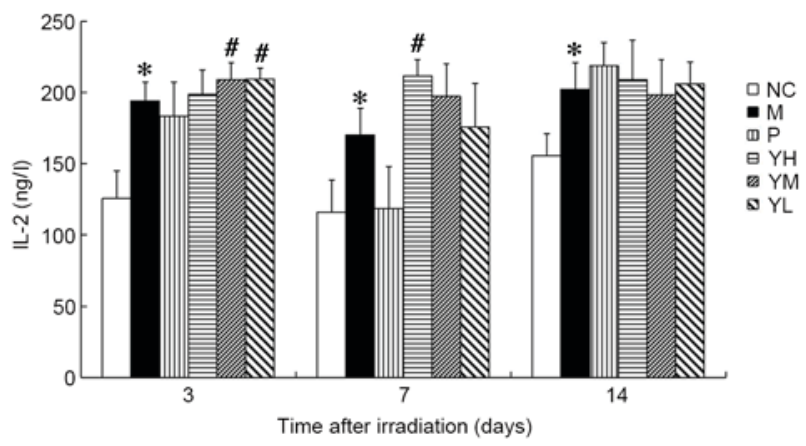

Figure 5. Effect of yak-activated protein on the serum IL-2 content of irradiated mice. Data are expressed as the mean + standard error of the mean. $\mathrm{n}=10$ per group. ${ }^{*} \mathrm{P}<0.05$ vs. normal control group, ${ }^{~} \mathrm{P}<0.05$ vs. model group. IL, interleukin; NC, normal control; $\mathrm{M}$, radiation model; $\mathrm{P}$, positive control; $\mathrm{YH}$, high dose $(10 \mathrm{mg} / \mathrm{kg})$ yak-activated protein; YM, middle-dose $(5 \mathrm{mg} / \mathrm{kg})$ yak-activated protein; YL, low-dose $(2.5 \mathrm{mg} / \mathrm{kg})$ yak-activated protein.

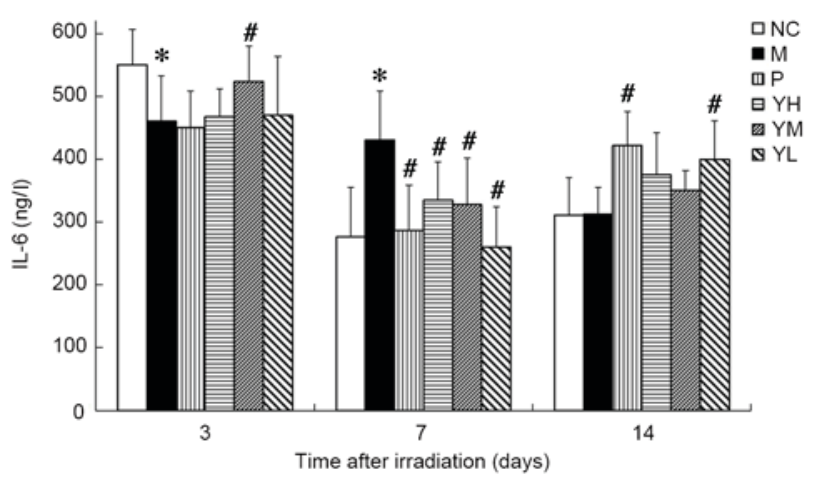

Figure 6. Effect of yak-activated protein on the serum IL-6 content of irradiated mice. Data are expressed as the mean + standard error of the mean. $\mathrm{n}=10$ per group. ${ }^{\mathrm{P}} \mathrm{P}<0.05$ vs. normal control group, ${ }^{\#} \mathrm{P}<0.05$ vs. model group. IL, interleukin; NC, normal control; M, radiation model; P, positive control; $\mathrm{YH}$, high dose $(10 \mathrm{mg} / \mathrm{kg})$ yak-activated protein; YM, middle-dose $(5 \mathrm{mg} / \mathrm{kg})$ yak-activated protein; YL, low-dose $(2.5 \mathrm{mg} / \mathrm{kg})$ yak-activated protein.

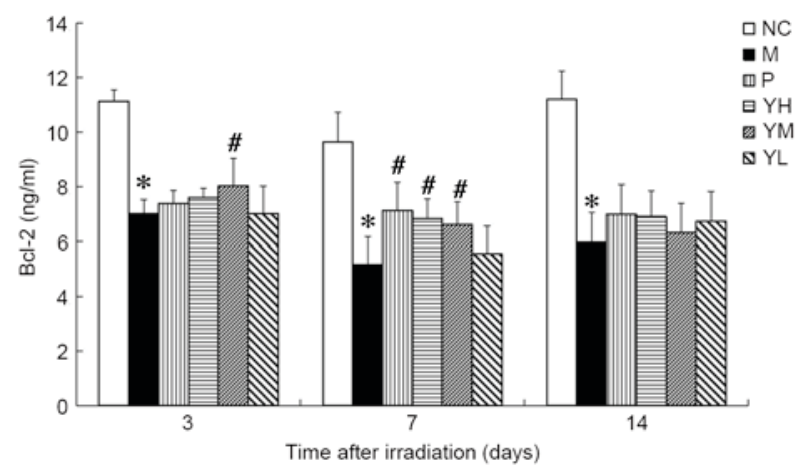

Figure 7. Effect of yak-activated protein on the expression of Bcl-2 in irradiated mice. Data are expressed as the mean + standard error of the mean. $n=10$ per group. ${ }^{*} \mathrm{P}<0.05$ vs. normal control group, ${ }^{\prime} \mathrm{P}<0.05$ vs. model group. $\mathrm{Bcl}-2$, $\mathrm{B}$ cell lymphoma 2; $\mathrm{NC}$, normal control; $\mathrm{M}$, radiation model; $\mathrm{P}$, positive control; YH, high dose $(10 \mathrm{mg} / \mathrm{kg})$ yak-activated protein; YM, middle-dose $(5 \mathrm{mg} / \mathrm{kg})$ yak-activated protein; YL, low-dose $(2.5 \mathrm{mg} / \mathrm{kg})$ yak-activated protein.

Bcl-2 and Bax expression. The expression of Bcl-2 was significantly reduced in the irradiation model group compared with the normal group at all time points $(\mathrm{P}<0.05$; Fig. 7). On day 3 ,

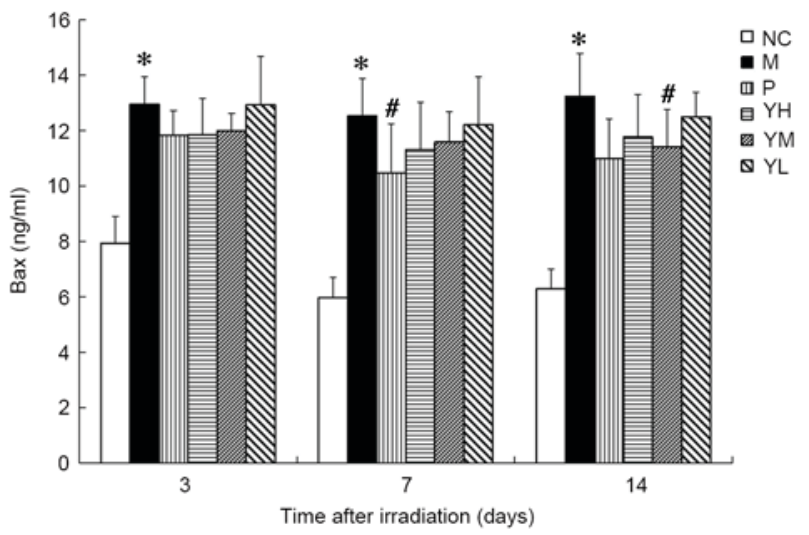

Figure 8. Effect of yak-activated protein on the expression of Bax in irradiated mice. Data are expressed as the mean + standard error of the mean. $\mathrm{n}=10$. ${ }^{*} \mathrm{P}<0.05$ vs. normal control group, ${ }^{~} \mathrm{P}<0.05$ vs. model group. Bax, $\mathrm{B}$ cell lymphoma 2-associated X protein; $\mathrm{NC}$, normal control; $\mathrm{M}$, radiation model; P, positive control; $\mathrm{YH}$, high dose $(10 \mathrm{mg} / \mathrm{kg})$ yak-activated protein; $\mathrm{YM}$, middle-dose $(5 \mathrm{mg} / \mathrm{kg})$ yak-activated protein; YL, low-dose $(2.5 \mathrm{mg} / \mathrm{kg})$ yak-activated protein.

the expression of $\mathrm{Bcl}-2$ was significantly higher in the medium dose yak-activated protein group compared with the model group ( $\mathrm{P}<0.05$; Fig. 7), and on day 7, levels of Bcl-2 were significantly increased in the positive control and medium and high dose yak-activated protein groups (all $\mathrm{P}<0.05$ vs. model group; Fig. 7). On day 14 following irradiation, Bcl-2 expression in the positive control and yak-activated protein groups did not differ significantly to that observed in the model group.

The expression of Bax was significantly increased in the irradiation group compared with the normal group at all time points $(\mathrm{P}<0.05$; Fig. 8). Relative to the radiation model group, Bax expression was significantly decreased in the positive control group on day $7(\mathrm{P}<0.05)$ and the medium-dose yak-activated protein group on day $14(\mathrm{P}<0.05$; Fig. 8). Marked decreases in Bax were also observed in the other treatment groups compared to the radiation model group following irradiation.

\section{Discussion}

The thymus and spleen are the most sensitive organs to ionizing radiation, and indices of the thymus and spleen may be used as indicators of immune system function (22). The results of the present study indicated that the spleen and thymus were significantly reduced in the radiation model group. Specifically, they were smaller in size and weight, and their indices were decreased compared with the normal control group, which is consistent with previous reports $(23,24)$. These results suggest that the radiation injury mouse model was successfully established. The administration of yak-activated protein lead to significant increases in the thymus and spleen indices, although they did not return to normal levels in the relatively short time assessed. It should be result of radiation, which leads to a long-term weakened immune system (25-27).

In the present study, levels of bone marrow DNA were measured to assess whether yak-activated protein protected mice from radiation. X-ray radiation affects DNA, biological membranes and water molecules in the body, and produces free 
radicals that interact with unsaturated fatty acids in the lipid bilayers of biological membranes (28). This leads to the destruction of macromolecular structures and single or double strand breaks in DNA, which blocks DNA synthesis and promotes gene mutations and apoptosis (29). In turn, these disruptions result in a decreased content of DNA and slower cell division, particularly for stem cells in the bone marrow (30). The results of the present study demonstrated that yak-activated protein significantly increased the content of DNA following irradiation, particularly in the high dose group on days 3 and 14 and the low dose group on day 7. This suggests that yak-activated protein may protect the DNA content in the bone marrow of irradiated mice, potentially through the prevention of DNA damage and stimulation of DNA synthesis.

Peripheral hemograms are considered to be key indicators of normal body function following radiation damage (31). Blood cells are the terminal cells of the blood system; therefore, changes in hematopoietic tissues reflect the degree of damage to the body, and X-ray irradiation typically decreases the number of blood cells in the body (32). In the present study, the numbers of WBCs, RBCs, HGBs and PLTs were assessed to evaluate the effects of yak-activated protein on the peripheral hemograms of radiation-injured mice. WBC, RBC, HGB and PLT counts declined following X-ray radiation; however, yak-activated protein inhibited this decrease and increased levels of RBCs, HGBs, and PLTs significantly. This suggests that yak-activated protein serves a key role in protecting the hematopoietic system against radiation-induced injury in mice.

IL-2 is a non-specific cytokine that is produced by helper $\mathrm{T}$ cells (33). It affects the activity and promotes the proliferation of activated $\mathrm{T}$ cells, stimulates $\mathrm{B}$ cells to produce antibodies, and significantly upregulates numerous factors, including monocytes and macrophages, associated with the immune system (33). Results of the present study demonstrated that $\mathrm{X}$-ray radiation reduced the self-regulatory capacity of the immune system, as indicated by reductions in IL-2 expression. However, yak-activated protein increased levels of IL-2 and potentially enhanced the humoral immune response following irradiation. The effects of yak-activated protein were most evident in the low and middle dose groups on day 3 , and in the high dose group on day 7. As indices of the thymus and spleen were also improved by yak-activated protein, these results suggest that yak-activated protein may stimulate $\mathrm{T}$ lymphocytes to produce IL-2 and facilitate recovery of the thymus and spleen. IL- 6 is a positive regulatory factor that exerts many biological effects, including stimulatory effects on cell proliferation and inhibitory effects on apoptosis (34). IL-6 is primarily associated with the regulation of hematopoiesis, inflammation and cellular immune responses in the body (34). Results of the present study demonstrated that levels of IL- 6 were decreased in the model group compared with the normal group on day 3 following irradiation, suggesting that ionizing radiation inhibited cell proliferation, accelerated cell apoptosis and reduced the secretion and expression of IL-6. However, similar to previous results (35), IL-6 content was significantly higher in the model group compared with the normal control group days 7 and 14 after radiation. IL- 6 content in each of the drug groups was higher than in the control and model groups. Levels of IL-6 were also significantly higher in the low-dose yak-activated protein group compared with the model group on days 7 and 14, suggesting that yak-activated protein may serve both positive and negative roles in the regulation of IL-6 following $\mathrm{X}$-ray irradiation.

Apoptosis is a primary pathway by which radiation-induced cell death occurs (36). Cellular apoptosis is regulated by complex and specific signal transduction pathways (36). The Bcl-2 family serves a key role in apoptosis, and the expression of Bcl-2 inhibits apoptosis and potentially promotes survival signaling to prolong cell longevity (37). Upon receipt of a death signal, the expression of Bax is upregulated in cells, leading to the formation of Bax multimers, altered membrane permeability and the release of pro-apoptotic factors into the cytoplasm to initiate apoptosis (30). Results of the present study indicated that X-ray irradiation significantly increased and decreased the expression of $\mathrm{Bax}$ and $\mathrm{Bcl}-2$, respectively. However, treatment with yak-activated protein lead to an upregulation in Bcl-2 and downregulation in Bax, suggesting that yak-activated protein may scavenge free radicals and inhibit increases in membrane permeability, thus reducing apoptosis. Therefore, yak-activated protein may exert radioprotective effects through the regulation of Bcl-2 and Bax.

In conclusion, results of the present study indicated that yak-activated protein may reduce damage induced by X-ray irradiation to peripheral blood cell counts, spleen and thymus indices, and bone marrow DNA content. Yak-activated protein may also improve the immune response and regulate the expression of anti- and pro-apoptotic proteins. Yak-activated protein is a high-efficiency and low-toxicity agent, which appears to protect against radiation. These results may serve as an experimental basis for further studies into radiation protection and the clinical applications of yak-activated protein.

\section{Acknowledgements}

The present study was supported by the National Natural Science Foundation of China (grant no. 81460568), the Program for New Century Excellent Talents in University of China (grant no. NCET-10-0917), the Natural Science Foundation of Qinghai Province of China (grant no. 2013-Z-909) and the Science Foundation of Qinghai University of China (grant no. 2014-QYT-2).

\section{References}

1. Wicki A, Witzigmann D, Balasubramanian V and Huwyler J: Nanomedicine in cancer therapy: Challenges, opportunities, and clinical applications. J Control Release 200, 138-157, 2015.

2. Chen L, Liu Y, Dong L and Chu X: Edaravone protects human peripheral blood lymphocytes from $\gamma$-irradiation-induced Apoptosis and DNA Damage. Cell Stress Chaperones 20: 289-295, 2015.

3. Staples JA, Ponsonby AL, Lim LL and McMichael AJ: Ecologic analysis of some immune-related disorders, including type 1 diabetes, in Australia: Latitude, regional ultraviolet radiation, and disease prevalence. Environ Health Perspect 111: 518-523, 2003.

4. Rouleau M, Patel A, Hendzel MJ, Kaufmann SH and Poirier GG: PARP inhibition: PARP1 and beyond. Nat Rev Cancer 10: 293-301, 2010.

5. Choi HN, Chung MJ, Park JK and Yong IP: Neuroprotective effects of N-Acetylglucosamine against hydrogen peroxide-induced apoptosis in human neuronal SK-N-SH cells by inhibiting the activation of caspase-3, PARP, and p38. Food Sci Biotechnol 22: 853-858, 2013. 
6. Koukourakis MI: Amifostine in clinical oncology: Current use and future applications. Anticancer Drugs 13: 181-209, 2002.

7. Hospers GA, Eisenhauer EA and de Vries EG: The sulfhydryl containing compounds WR-2721 and glutathione as radio-and chemoprotective agents. A review, indications for use and prospects. Br J Cancer 80: 629-638, 1999.

8. Li HY, Zhao Y, Sun XD, Bai XZ and Zhao DQ: Effect of ginseng protein against radiation injury in mice. Shizhen Guo Yi Guo Yao 21: 2143-2144, 2010 (In Chinese).

9. Deng Q, Chen C, Duan H, Wang L and Xie B: Protection effect of ginkgo albumin extract on $\gamma$-ray irradiated mice. J Radiat Res Radiat Process 23: 360-365, 2005 .

10. Wei C: The effects of lactoferrin against injuries induced by radiation (unpublished masters thesis). Jinan University, 2013 (In Chinese).

11. Guinan EC, Barbon CM, Kalish LA, Parmar K, Kutok J, Mancuso CJ, Stoler-Barak L, Suter EE, Russell JD, Palmer CD, et al: Bactericidal/permeability-increasing protein (rBPI21) and fluoroquinolone mitigate radiation-induced bone marrow aplasia and death. Sci Transl Med 3: 110ra118, 2011.

12. Wen J, Zhao J, Bi X, Jin ZL, Jin RY and Ru BG: The experimental study on anti-radiation effect of metallothionein. Ying Yang Xue Bao 23: 44-47, 2001 (In Chinese).

13. Seed TM, Inal CE and Singh VK: Radioprotection of hematopoietic progenitors by low dose amifostine prophylaxis. Int J Radiat Biol 90: 594-604, 2014.

14. Ren GP, Li YY and Gu WY: Advancement in physiological function of gln - A conditionally essential amino acid and its use in nutrition. Anjisuan He Shengwu Ziyuan 23: 39-43, 2001 (In Chinese)

15. Suh SS, Hwang J, Park M, Seo HH, Kim HS, Lee JH, Moh SH and Lee TK: Anti-inflammation activities of mycosporine-like amino acids (MAAs) in response to UV radiation suggest potential anti-skin aging activity. Mar Drugs 12: 5174-5187, 2014

16. Wakabayashi H, Yamauchi $\mathrm{K}$ and Takase $\mathrm{M}$ : Lactoferrin research, technology, and applications. Int Dairy J 16: 1241-1251, 2006.

17. Xu B, Yao X, Tie J, Lu D, Yuan M, Li Y, Zhu J and Li X: The immunoregulation effect of yak activated protein on murine immune system. J Qing hai Med College 34: 54-56, 2013.

18. Marusyk A, Casás-Selves M, Henry CJ, Zaberezhnyy V, Klawitter J, Christians U and DeGregori J: Irradiation alters selection for oncogenic mutations in hematopoietic progenitors. Cancer Res 69: 7262-7269, 2009

19. Song JY, Yang HO, Shim JY, Ji-Yeon-Ahn, Han YS, Jung IS and Yun YS: Radiation protective effect of an extract from Chelidonium majus. Int J Hematol 78: 226-232, 2003.

20. Zhang Y, Wu H and Guan XJ: Effect of prophylactic administration with angelica polysaccharides on expression of adhesion molecules and cell cycle of bone marrow mononuclear cells of radiation injured mice. Chin J Biologicals 23: 627-631, 2010.

21. Xie XD, Su G, Nian XF, Ma GR and Jia ZP: Protective effect of chondroitin sulfate-A on X-ray irradiated mice. J Northwest Normal University (Natural Science) 49: 86-90, 2013.

22. Fang JJ, Zhu ZY, Dong H, Zheng GQ, Teng AG and Liu AJ: Effect of spleen lymphocytes on the splenomegaly in hepatocellular carcinoma-bearing mice. Biomed Environ Sci 27: 17-26, 2014.

23. Fan ZL, Wang ZY, Zuo LL and Tian SQ: Protective effect of anthocyanins from lingonberry on radiation-induced damages. Int J Environ Res Public Health 9: 4732-4743, 2012
24. Tajima G, Delisle AJ, Hoang K, O'Leary FM, Ikeda K, Hanschen M, Stoecklein VM and Lederer JA: Immune system phenotyping of radiation and radiation combined injury in outbred mice. Radiat Res 179: 101-112, 2013.

25. Choi HN, Chung MJ, Park JK and Park Y: Neuroprotective effects of N-Acetylglucosamine against hydrogen peroxide-induced apoptosis in human neuronal SK-N-SH cells by inhibiting the activation of caspase-3, PARP and p38. Food Sci Biotechnol 22 853-858, 2013.

26. Wei S, Egenti MU, Teitz-Tennenbaum S, Zou W and Chang AE: Effects of tumor irradi-ation on host T-regulatory cells and systemic immunity in the context of adoptive T-cell therapy in mice. J Immunother 36: 124-132, 2013.

27. Xie P, Qin ZY and Tang MJ: Research developments in anti-radiation effects of polysaccharide. Zhongguo Fu She Wei Sheng 19 507-509, 2010 (In Chinese).

28. Bhilwade HN, Jayakumar S and Chaubey RC: Age-dependent changes in spontaneous frequency of micronucleated erythrocytes in bone marrow and DNA damage in peripheral blood of Swiss mice. Mutat Res Genet Toxicol Environ Mutagen 770: 80-84, 2014

29. Yao XC and Li XY: Research advance about anti-radiation effect of protein. Shandong Yi Yao 54: 88-90, 2014 (In Chinese).

30. Johnke RM, Sattler JA and Allison RR: Radioprotective agents for radiation therapy: Future trends. Future Oncol 10: 2345-2357, 2014.

31. Lin Z, Nei M and Ma H: The origins and early evolution of DNA mismatch repair genes-multiple horizontal gene transfers and co-evolution. Nucleic Acids Resr 35: 7591-7603, 2007.

32. Widel M, Jedrus S, Lukaszczyk B, Raczek-Zwierzycka K and Swierniak A: Radiation-induced micronucleus frequency in peripheral blood lymphocytes is correlated with normal tissue damage in patients with cervical carcinoma undergoing radiotherapy. Radiat Res 159: 713-721, 2003.

33. He Y, Fang J, Peng X, Cui H, Zuo Z, Deng J, Chen Z, Lai W, Shu G and Tang L: Effects of Sodium Selenite on Aflatoxin B1-induced decrease of ileac T cell and the mRNA Contents of IL-2, IL-6, and TNF- $\alpha$ in Broilers. Biol Trace Elem Res 159: 167-173, 2014.

34. Schulte-Herbrüggen O, Nassenstein C, Lommatzsch $M$, Quarcoo D, Renz H and Braun A: Tumor necrosis factor-alpha and interleukin- 6 regulate secretion of brain-derived neurotrophic factor in human monocytes. J Neuroimmunol 160: 204-209, 2005.

35. Wang YH, Jiang LZ, Li Q and Zhong XH: Effect of high power microwave radiation on liver injury and serum cytokine in rats. Acadedemic J Second Military Medical University 35: 672-675, 2014.

36. Raj PV, Nitesh K, Prateek J, Sankhe MN, Rao JV, Rao CM and Udupa N: Effect of Lecithin on D-galactosamine induced hepatotoxicity through mitochondrial pathway involving Bcl-2 and Bax. Ind J Clin Biochem 26: 378-384, 2011

37. Chipuk JE, Kuwana T, Bouchier-Hayes L, Droin NM, Newmeyer DD, Schuler M and Green DR: Direct activation of Bax by 53 mediates mitochondrial membrane permeabilization and apoptosis. Science 303: 1010-1014, 2004. 